\title{
The Development Trend of Environmental Protection Industry Stimulated by Financial policy
}

\author{
${ }^{1 \text { st }}$ Shengting $\mathrm{LI}^{1, \mathrm{a}}$, ${ }^{\text {2nd }}$ Xiaowei ZHOU ${ }^{2, \mathrm{~b}}$ \\ ${ }^{1}$ International Business School, Shaanxi Normal University, SNNU, Xi'an, China \\ ${ }^{2}$ International Business School, Shaanxi Normal University, SNNU, Xi'an, China
}

\begin{abstract}
The development of environmental protection industry (EPI) has connection with many factors, such as policy, market and economic factors. Different factors have complex mutual influence, and the sensitivity of EPI to policy is higher than other industries, so its development has its own characteristics. This paper adopted the method of system dynamics (SD) to analyze the promoting effect of Financial policy on the development of EPI regarding the environmental protection market (EPM) as the carrier of EPI, and taking the Supply and the market concentration degree (MCD) as the characterization object. The research conclusion shows that Financial policy has an obvious effect on both Supply and MCD, among which the effect on Supply shows a constant scale effect, while the effect on MCD shows a decreasing scale effect.
\end{abstract}

\section{Introduction}

In August 2017, the general office of the state council issued "the opinions on promoting third-party treatment of environmental pollution", aiming to solve environmental externalities caused by economic development in a market-oriented way. The cultivation and development of environmental protection industry (EPI) reflects the multi-dimensional demands of industrial upgrading, market deepening and environmental governance. The operation revenue of EPI was about 1.78 trillion yuan, with the year-on-year growth of $11.3 \%$. This is much higher than the growth rate of the national economy in the same period, reflecting a strong development momentum of EPI. Even so, China's EPI still has considerable room for improvement, because the contribution rate of the output value of EPI reached more than $20 \%$ in the United States and other developed countries. China's EPI structure meanwhile is not fully developed. Small and micro enterprises account for more than $90 \%$, indicating EPI has not yet formed a significant scale effect and a reasonable degree of concentration, and the role of the market mechanism has not yet fully played. It can be understood that growth effect of EPI is not prominent, although the investment keeping growing and corresponding policy support. The EPI of China is still in the incubation period, no matter measured by the output of EPI or the market size. As a derivative of manufacturing industry, EPI has a natural dependence and deeply coupled cooperative relationship with manufacturing industry at the same time. This deep association leads to the common demand of factor market and knowledge sharing between them, which has a natural cooperative agglomeration basis. EPI has dual attributes of producer services and manufacturing, and itself has been included in the collaborative agglomeration of producer services and manufacturing. As a result, the scale and structure of manufacturing industry will inevitably have an important impact on the development of EPI. In addition, EPI has a high degree of policy sensitivity, and the formulation and implementation of environmental regulations and financial policies can not be ignored on the environmental protection market. Under the joint action of many factors, the development trend of EPI and its internal mechanism need to be further discussed.

\section{Review of related literature}

Financial policy plays an important role in industrial development. The research of Rodrik (2008) shows that the implementation effects of the same industrial incentive policies is not the same in different countries, which have different history, culture, tradition, political and economic structure and other aspects[1]. HUANG XiaoYing (2017) applied DEA-Tobit method to analyze the Financial policy efficiency of China's EPI and its influencing factors, founding that the pure technical efficiency of Financial policy for EPI was low; growth of EPI is highly dependent on national policies and has great regional heterogeneity [2]. HUANG QingZi (2016) constructed the GRA-VAR model and compared several policy tools in EPI by measuring their importance and influence, through measuring the importance and influence of policy tools on EPI and the differences of 
several policy tools compared, and concluded that scientific and technological policy tools were the best, followed by economic policy tools and legal policy tools were the weakest to incent the growth of EPI [3]. LIN Dejian (2018) empirical analysis results show that the effect of Financial policy to EPI development is mainly manifested in capital investment, however, different types of Financial policy factors play different roles. The direct financial system dominated by capital market plays a more significant supporting role than the indirect financial system dominated by bank credit [4]. WU Qian (2018) believes that green finance can effectively solve the problem of financial investment in EPI, drive economic progress, improve industrial internal structure and accelerate the development of EPI [5]. LIU Xiliang and WEN Shuyang (2018) did empirical analysis and proved that the financial machine Structural credit decision can significantly affect the quality of economic growth [6].

The above scholars have studied the impact and role of Financial policy on industrial development from different perspectives, however, there are few studies on the development of EPI based on financial support. As an emerging industry, EPI has its own particularity in development, this paper focuses on the impact of Financial policy on EPI.

\section{System dynamics model of EPI}

\subsection{SD model construction}

The integrity, complexity, non-linearity and interaction of systems are emphasized in System theory, and the internal relations and evolution of the system are studied and speculated, by abstracting and simulating. SD is a systematic research method combining path feedback, control simulation and quantitative analysis. In this paper, SD method was adopted to describe the development path and trend of EPM system under the influence of multiple external and internal factors, based on the relevant data of China's EPI from 2007 to 2016(data from the website of the national bureau of statistics,
China environmental statistics yearbook and CSMAR database). The market is a very complex system, and this model cannot cover all the internal and external factors of EPM and their influences, however, we try to grasp the key factors and the main trend, through the fitting, simulation and test of the real data, so as to reflect the law more truly and fully.

The development of EPI and the market are closely linked with each other. If only observing the output scale as a single indicator, it is impossible to examine the market in the structure and maturity of the variation trend, while the improvement and optimization of the market is the key variable of industrial upgrading and the core factor of ensuring the sustainable development of the industry. In this paper, the two indicators of market supply and market concentration(MC) of EPI are selected as the representative variables to reflect the development degree and status of EPI from two aspects of output scale and market structure.

Based on the above analysis, the construction of this research model is based on the following basic assumptions: (1) The basic model of EPM dynamic evolution system was constructed from the perspective of supply and demand balance, and the initial state of supply and demand balance in 2007 was assumed. (2) Two variables, Supply and MC were used to analyze the development trend of EPI. (3) MOIP are described in the form of index.

\subsubsection{Parameter setting}

Vensim PLE software is used for simulation, the simulation period is set to 10 years, and step length-DT is set to 1 year. The initial values of the horizontal variables (such as the QEPE, EPM supply and demand) were the statistical data in 2007, Financial policy and tax incentives are all expressed in index (without units), Other data units related to the quantity of revenue and expenditure are unified as 100 million Yuan. The simulation results are shown in fig 1 below.

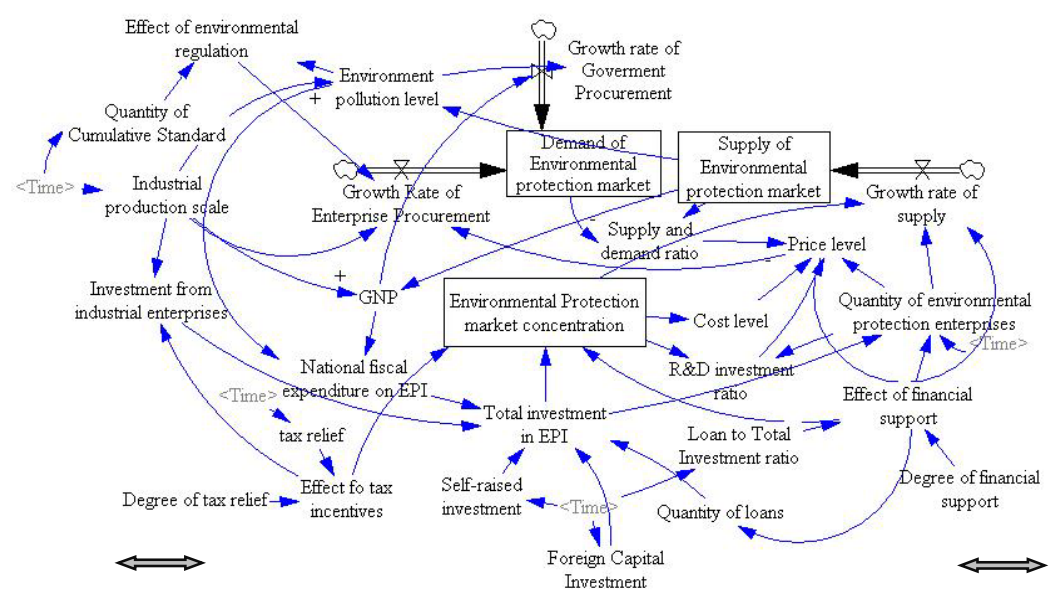

Fig 1 The dynamic model of EPI incented by financial support 


\subsubsection{Description of major variables}

Tab 1 System main variables description

\begin{tabular}{|c|c|}
\hline relevant variable & variable declaration \\
\hline Environment Pollution Level(EPL) & $\begin{array}{c}\text { Referring to TIAN Shizhong }(2017)^{[7]} \text {, the statistical average of pollution } \\
\text { index }\end{array}$ \\
\hline GNP & Gross National Product \\
\hline Industrial Production scale & Added value of the secondary industry \\
\hline $\begin{array}{l}\text { Market Concentration } \\
\text { degree }(\mathrm{MCD})\end{array}$ & fixed assets proportion of top three enterprises in EPI \\
\hline $\begin{array}{c}\text { Quantity of Environmental } \\
\text { Protection Enterprises(QEPE) }\end{array}$ & quantity of enterprises whose main business is environmental protection \\
\hline R\&D Investment ratio & $\begin{array}{c}\text { R\&D investment/operating income of listed environmental protection } \\
\text { enterprises }\end{array}$ \\
\hline $\begin{array}{l}\text { Growth Rate of Enterprise } \\
\text { Procurement }\end{array}$ & $\begin{array}{l}\text { Growth rate of ratio of environmental protection expenditure to operating } \\
\text { income of listed industrial enterprises }\end{array}$ \\
\hline $\begin{array}{l}\text { Growth Rate of Government } \\
\text { Procurement }\end{array}$ & Growth rate of total national fiscal expenditure on environmental protection \\
\hline Self-raised Investment & Self-raised funds for fixed asset investment in EPI \\
\hline Foreign Capital Investment & Foreign fixed assets investment to EPI \\
\hline Quantity of Cumulative Standard & Total of local environmental protection standards issued \\
\hline Tax Relief & Tax refund/payable tax of listed environmental protection enterprises \\
\hline Loan to Total Investment ratio & loan of fixed assets investment /total fixed assets investment of EPI \\
\hline
\end{tabular}

\subsection{Analysis of simulation result}

In the model, the base period is defined as the system state when Financial policy were preset to 0 .

The Financial policy effect is manifested as the influence on the proportion of loan in investment of EPI. When the random fluctuation function is used to control the Financial policy degree at the level of $0 \% \sim 80 \%$, the stress effect of Supply and MC is shown in fig2 and fig3 below.

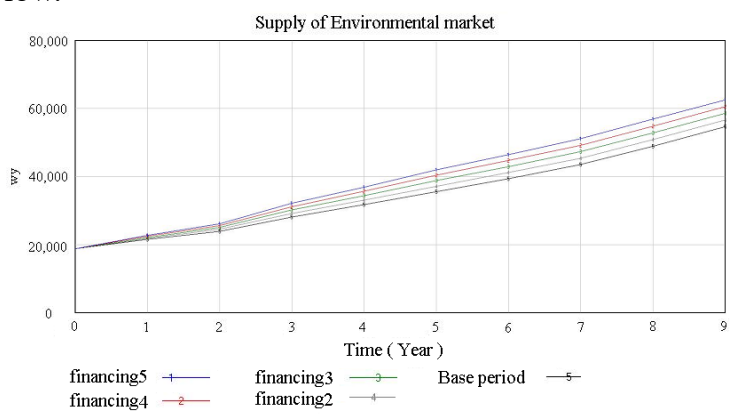

Fig2 Impact of Financial policy on Supply

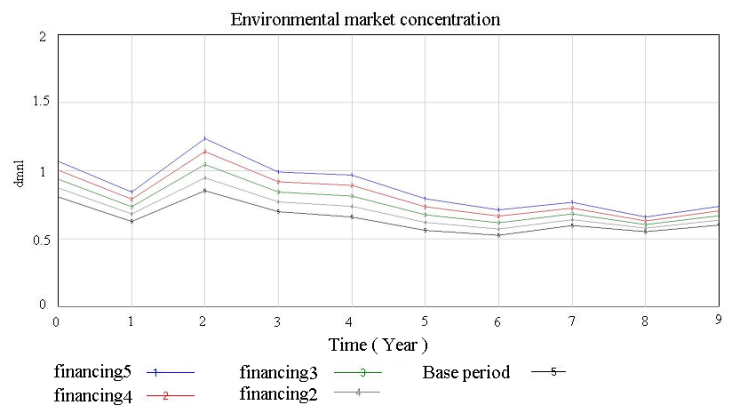

Fig3 Impact of Financial policy on MCD

Financial policy policies have a significant effect on improving the supply of EPI. At each level, the incentive effect gradually appears after DT $=1 \sim 2$, and the growth rate is $3.28 \% \sim 3.60 \%$ respectively. With continuous improvement of financial support, the growth rate of supply of EPM remains at a relatively stable level. The $\mathrm{MC}$ shows a certain fluctuation trend in the simulation period at all levels, and the fluctuation is gradually digested in the later simulation period. Under continuous enhancement of financial support, the growth rate of MC is from $4.91 \%$ to $5.77 \%$, with slow convergence. Financial policy has a promoting effect on the supply of EPM, showing the characteristic of constant scale effect, but the incentive effect on MC has the phenomenon of diminishing scale effect.

\section{Conclusion analysis and policy recommendations}

This article adopted related data of EPI in 2007-2016, and analyzed the mechanism of Financial policy impacting EPI, constructing the SD model of EPI. We can draw the following conclusion based on the above analysis. The effect of Financial policy on supply shows the feature of constant scale effect, and the effect of Financial policy on the increase of MCD shows the feature of decreasing scale effect.

For the above results, this paper believes that the reasons are as follows: From the perspective of the value chain, Financial policy plays a role at the beginning of the value chain in the EPI system, by stimulating environmental investment to indirectly promote supply growth. It can be understood as an indirect incentive to supply. On the other side, the major companies have better absorptive capacity of financial resources and social influence factors, thus it is easier to obtain advantage support from the policy system, and the policy support also has a certain tendency for major enterprises. A positive feedback loop works consequently, then the advantages of dominant enterprises are continuously amplified in the market, and the MC level is correspondingly increased. 
Accordingly, the following proposal was put forward: the role of Financial policy in the adjustment of the market structure of EPI cannot be ignored. Financial policy has not performed as well as tax incentives in stimulating Supply, however has the function of ironing out shock and stabilizing market in the adjustment of market structure, so government should guide financial institutions in the banking sector to strengthen the link between industry and finance, deepen the application of the green credit assessment mechanism, and urge banking sector to increase Financial policy for environmental protection enterprises and projects.

This paper investigated the unidirectional promotion effects of Financial policy to EPI, and it should be further studied that the interaction of various factors under different subdivision dimensions of the two policies.

\section{Acknowledgments}

This paper is supported by the Soft Science Project of Shaanxi Provincial, "Economic and Ecological Effects of Collaborative Agglomeration between Manufacturing Industry and Environmental Protection Industry in Xi 'an High-tech Zone" (No. 2020RZ011)

\section{References}

1. Danny Roderick. Same economics, different policy prescriptions[M]. ZHANG Junkuo, HOU yongzhi, trans. Beijing: citic press,2008:97-142.

2. HUANG Xiaoying, Wen Lirong. Research on the Efficiency and Influencing Factors of Financial policy for the Enterprises in Energy-saving and Environmental Protection Industry[J]. Economy and Management, 2017,31(1):45-50.

3. HUANG Qingzi, WANG Zhenzhen, WANG Lijian. An empirical analysis of policy instrument comparison in China's environmental industry according to GRA-VAR modeling [J]. Resource Science, 2016,38(10):1988-2000.

4. LIN Dejian, CHEN Jiali, QIU Guoyu. Research on Green Financial policy Factors of China's Environmental Protection Industry-An Empirical Analysis Based on the Constituent Stocks of the CSI Environmental Protection Industry 50 Index [J]. Journal of Industrial Technological Economics,2018, 37(05):129-135.

5. WU Qian. Boosting Effect of Green Finance on
Development of Environmental Protection Industry[J]. Environmental Science and Management ,2018,43(06):167-170.

6. LIU Xiliang and WEN Shuyang. Should Financial Institutions be Environmentally Responsible in China? Facts, Theory and Evidence[J]. Journal of Industrial Technological Economics, 2019(03):38-54[2019-04-01].

7. TIAN Shizhong. The Comprehensive Evaluation of Environmental Pollution from the Perspective of Fiscal Decentralization in China: 1998-2015- An Empirical Study Based on the Panel Data of Provincial Industrial Pollution [J]. East China Economic Management, 2017,31(05):34-41.

8. Aghion P, Dewatripont M, Luosha D, et al. Industrial policy and competition[Z]. NBER Working Paper, No.18048, 2012.

9. Boyd, G. A, and J. D. Mcclell. The Impact of Environmental Constraints on Productivity Improvement in Integrated Paper Plants[J]. Journal of Environmental Economics and Management, 1999, 38 (2): 121-142.

10. Eli Berman. Environmental Regulation and Productivity: Evidence from Oil Refineries[J]. Reserrch of Environmental Science,2001, 83 ( 3 ) : $498-510$.

11. Zhang J.X., Liu Y.M., Chang Y., Zhang L.X. Industrial eco-efficiency in China: a provincial quantification using three-stage data envelopment analysis[J]. Clean.Prod. ., 2017,143: 238-249.

12. Zhang J.X., Chang Y., Zhang L., Li D. Do technological innovations promote urban green development?-A spatial econometric analysis of 105 cities in China.[J]. Clean. Prod. 2018,182:395-403.

13. Zhang K.The emission reduction effects of economic agglomeration: an explanation based on spatial economics[J]. Ind. Econ. Res. 2018,3: 64-76.

14. Zhang K., Dou J M.Does industrial agglomeration reduce emissions?[J]. Huazhong Univ. Sci. Technol. (Nat. Sci. Ed.) 2016,30 (4):99-109.

15. Zheng Q., Lin B. Impact of industrial agglomeration on energy efficiency in China's paper industry[J].Clean. Prod. 2018,184:1072-1080.

16. Zhou M.S., Wang S. Is industrial agglomeration the "killer" that leads to regional environmental pollution? [J].Ref. Econ. Sys.2018, 5: 185-190. 